\title{
Anticancer Effects of Antihypertensive L-Type Calcium Channel Blockers on Chemoresistant Lung Cancer Cells via Autophagy and Apoptosis
}

This article was published in the following Dove Press journal: Cancer Management and Research

\author{
Bing-Sang Wong' \\ Ling-Yen Chiu ${ }^{2}$ \\ Dom-Gene Tu ${ }^{2,3}$ \\ Gwo-Tarng Sheu (iD) ${ }^{4-6, *}$ \\ Ting-Tat Chan ${ }^{7, *}$ \\ 'Division of Neurosurgery, Antai Medical \\ Care Corporation Antai Tian-Sheng \\ Memorial Hospital, Pingtung County, \\ Taiwan; ${ }^{2}$ Department of Nuclear \\ Medicine, Ditmanson Medical \\ Foundation, Chia-Yi Christian Hospital, \\ Chiayi City, Taiwan; ${ }^{3}$ Department of \\ Biomedical Sciences, National Chung \\ Cheng University, Chiayi 62102, Taiwan; \\ ${ }^{4}$ Institute of Medicine, Chung Shan \\ Medical University, Taichung, Taiwan; \\ ${ }^{5}$ Immunology Research Center, Chung \\ Shan Medical University, Taichung, \\ Taiwan; ${ }^{6}$ Department of Medical \\ Oncology and Chest Medicine, Chung \\ Shan Medical University Hospital, \\ Taichung, Taiwan; ${ }^{7}$ Palliative Care Unit, \\ Department of Family Medicine, Ditmanson \\ Medical Foundation, Chia-Yi Christian \\ Hospital, Chiayi City, Taiwan
}

*These authors contributed equally to this work
Correspondence: Gwo-Tarng Sheu Institute of Medicine, Chung Shan Medical University, No. II0, Sec. I, Jianguo N. Road, Taichung City 402, Taiwan

Tel +886-4-24730022 Ext II 692

Fax +886-4-2475 I I0I

Email raymondsheu@gmail.com
Purpose: Hypertension and cancer are frequently found comorbidity occurring in same individual. This study was intended to evaluate the anticancer effects of commonly used antihypertensive medications and chemotherapy on chemoresistant lung cancer cells.

Methods: Calcium channel blockers (CCBs), including Verapamil, Diltiazem, and Nifedipine, either alone or combined with docetaxel (DOC) or vincristine (VCR) were used to treat A549 lung adenocarcinoma chemoresistant sublines. Cell viability was determined by MTT assay, and colony formation assay was used to demonstrate the long-term effect of CCBs on proliferation of the sublines. Apoptosis was evaluated by Annexin V assay and autophagy intensity was quantitated from acidic vesicular organelle formation. Pan-caspase inhibitor, shATG5 interference and chloroquine were applied to study the roles of Verapamil on apoptosis and autophagy, with related proteins verified by Western blot analysis.

Results: Results show that $10 \mu \mathrm{M}$ of Verapamil and Diltiazem, but not Nifedipine, differentially induce autophagy in DOC-resistant or VCR-resistant A549 cells, respectively. When CCBs are combined with DOC or VCR to treat the sublines, $10 \mu \mathrm{M}$ of Verapamil induces autophagy more significantly than Diltiazem and Nifedipine, respectively, in DOC-resistant $(54.91 \pm 0.76,18.03 \pm 0.69,7.05 \pm 0.30)$ or VCR-resistant A549 $(32.41 \pm 1.04,21.51 \pm 0.63,7.14$ $\pm 0.24)$ cells. Inhibition of apoptosis by pan-caspase inhibitor partly reduced cell death indicates association of caspase-dependent cell death but with persistence of autophagy. Inhibition of autophagy by interfering ATG5 expression reduced c-PARP level and apoptotic cells suggest a pro-death role of autophagy. Chloroquine treatment enhanced autophagosome accumulation and cell death but with reduced c-PARP level suggests that mechanism of caspase-independent cell death also contributes to Verapamil/chemotherapy-induced anticancer effects.

Conclusion: Verapamil combined with DOC or VCR induces chemoresistant lung cancer cells to death through autophagy burst and apoptosis more strongly than Diltiazem and Nifedipine. Administering Verapamil or Diltiazem individually with chemotherapy, but not Nifedipine, can be considered in lung cancer patients with hypertension.

Keywords: hypertension, calcium channel blockers, lung cancer, Verapamil, Diltiazem, Nifedipine, chemoresistance

\section{Introduction}

Eighty percent of lung cancer cases are non-small cell lung cancer (NSCLC). The 5 -year survival rate for lung cancer $(18 \%)$ is next to pancreas cancer $(8 \%)$, the lowest of all cancers; ${ }^{1}$ and chemotherapy is generally suggested for treatment of advanced-stage cancers. However, initial chemotherapy often leaves residual 
disease, from which tumors recur, and this multidrug resistance (MDR) limits the efficacy of chemotherapy. ${ }^{2}$ In addition to the resistance caused by regulation of drug transporters, such as $\mathrm{ABCB} 1$, the mechanisms of resistance to "classical" cytotoxic chemotherapeutics share many features, such as alterations in the target of drug, activation of prosurvival pathways and ineffective induction of cell death. ${ }^{3}$

Docetaxel (DOC) has anti-mitotic properties through the binding to microtubules (MTs) and preventing of depolymerization and stabilization of MTs. ${ }^{4}$ Vincristine (VCR) is a classic anti-tubulin agent that induces disruption of MTs by binding to tubulin and inhibits tubulin polymerization/MT formation. ${ }^{5}$ The action of VCR differs from that of DOC, which destabilizes MTs. Both $\mathrm{DOC}^{6,7}$ and $\mathrm{VCR}^{8,9}$ have been applied clinically as part of various cancer chemotherapy regimens. However, both drugs are a substrate of the $\mathrm{ABCB} 1$ transporter P-gp, so overexpression of $\mathrm{ABCB} 1$ in cancer cells is considered the major phenotype of multidrug resistance to DOC and VCR. ${ }^{10,11}$

There are many classes of antihypertensive, which lower blood pressure by different means. Among the most important and most widely used drugs are calcium channel blockers (CCBs), thiazide diuretics (TD), angiotensin-converting enzyme inhibitors (ACEi), angiotensin II receptor antagonists (ARBs), and beta blockers (BBs). ${ }^{12}$ L-type CCBs block the transmembrane flow of calcium, resulting in antagonism of vascular smooth muscle, contraction of myocardial smooth muscle, reduction of blood pressure, and coronary artery dilation. ${ }^{13,14}$ CCBs have assumed a major role in the treatment of patients with hypertension or coronary artery disease. CCBs can be broadly classified into 2 groups: dihydropyridine (DHP), such as Nifedipine (a 1,4-dihydropyridine, NIF); and nondihydropyridine (non-DHP) groups. The prototypical agents of non-DHP group are Verapamil (a phenylalkylamine, VER), and Diltiazem (a benzothiazepinone, DIL). CCBs were the ninth most commonly prescribed class of drugs in the United States in 2009, with over 90 million prescriptions filled. ${ }^{15}$

To overcome the high prevalence of MDR, researchers have developed $\mathrm{ABC}$ transporter inhibitors to increase the intracellular concentration of chemotherapy drugs. ${ }^{16}$ In the early 1980s, it was found that CCBs are inhibitors of MDR in leukemia cells, ${ }^{17,18}$ and VER was the first compound to reach clinical trial for its ability to reverse MDR. ${ }^{16}$ Though some clinical trials failed due to high toxicity of VER or absence of improvement in the clinical outcome, ${ }^{19}$ others showed that VER improves patient survival, ${ }^{20-23}$ including a randomized study of NSCLC. ${ }^{24}$

The association between antihypertensive medications and the survival in cancer patients remains unclear. A recent report has documented survival in patients with common cancers who had been prescribed BBs, ACEi/ ARBs, CCBs or TD for a minimum of one year prior to diagnosis of cancer, based on the provincial Drug Program Information Network. ${ }^{25}$ Cancer patients who were users of each class of antihypertensive agent were compared to cancer patients who were non-users of antihypertensive drugs. The survival of patients using only one drug class was compared, with BBs serving as the reference class. Compared to the antihypertensive drug non-user cohort, BBs had no effect on survival for any of the cancers. ACEi/ARBs use was weakly associated with increased deaths for breast cancer and lung cancer patients. Deaths were also increased with CCB use in patients with breast cancer and with TD use in lung cancer patients. When including only antihypertensive drug users prescribed with one drug class, lung cancer patients receiving CCBs had improved survival compared to BBs. This may be explained by a previous report that $\mathrm{CCBs}$ promote the sensitivity of multidrug-resistant lung cancer cells to chemotherapy. ${ }^{3}$

Autophagy is a cellular process responsible for delivering proteins or organelles to lysosomes. ${ }^{26}$ It not only helps maintain cellular homeostasis but also promotes survival during cellular stress situations. In contrast, excessive autophagy also promotes death of cancer cells. ${ }^{27}$ Therefore, autophagy seems to be a double-edged sword in the context of cancer therapies. It has been found that VER induces autophagy that reveals a cyclical mTORindependent pathway regulating autophagy. ${ }^{28}$ Increased calcium influx is found in mononuclear cells (MNC) of patients with systemic lupus erythematosus (SLE), and NIF can promote SLE-MNC apoptosis. ${ }^{29}$ In addition, DIL may induce prostate cancer cell death, which could make it a drug of choice for treating cancer associated with hypertension. $^{30}$ Interestingly, the sodium channels expressed in highly invasive breast cancer cell line MDA-MB-231 are sensitive to CCBs such as VER and DIL, but not to NIF with reduced cell proliferation. ${ }^{31}$ Currently, there is no conclusive cellular mechanism that explains the observed association between CCB use and lung cancer survival/outcome. Therefore, this study demonstrate the anticancer effects of CCBs, either alone or combined with chemotherapy, in chemoresistant A549 
cells. It provides suggestions for using CCBs differentially in hypertension with lung cancer comorbidity. This investigation thus offers new proposals for appropriate application of CCBs in lung chemotherapy when patients also under hypertension management.

\section{Methods}

\section{Drugs and Chemicals}

DOC was obtained from Aventis Pharmaceuticals Inc. (Bridgewater, NJ). VCR, VER, NIF, DIL, and Chloroquine diphosphate salt were obtained from Sigma-Aldrich (St. Louis, MO). Z-VAD-FMK was purchased from Bachem (Torrance, CA). U0126 was purchased from Cell Signaling (Danvers, MA).

\section{Chemoresistant Subline and Viability MTT Assay}

Human adenocarcinoma A549 cells (ATCC, Manassas, VA, USA) were maintained as previously described. ${ }^{3}$ DOC- and VCR-resistant sublines were established from parental cells by exposure to increasing concentrations of DOC or VCR in a stepwise manner. The DOC-resistant subline maintained at 16 nM DOC is denoted A549/D16 and identified as P-gp overexpressing cells. A similar designation, A549/V16, was given to a VCR stably resistant subline and this subline is P-gpindependent. ${ }^{3}$ Cell viabilities were determined on MTT colorimetric assay. Briefly, cells $\left(2 \times 10^{4} /\right.$ per well) were seeded onto 24-well plates. After $24 \mathrm{hrs}$ incubation, the cells were exposed to various concentrations of DOC or VCR or CBCs in fresh medium for $48 \mathrm{hrs}$. Cells were washed with PBS, and MTT (300 $\mu \mathrm{L} /$ well, $1 \mathrm{mg} / \mathrm{mL}$; Sigma) was added before further incubation at $37^{\circ} \mathrm{C}$ for $2.5 \mathrm{hrs}$. Cells were washed with PBS, and 2-propanol solution ( $300 \mu \mathrm{L} /$ well) was added to dissolve the water-insoluble formazan salt with shaking at $70 \mathrm{rpm}$ for $10 \mathrm{~min}$ at room temperature. Finally, the absorbance $(570 \mathrm{~nm})$ was measured using an ELISA plate reader (Molecular Devices SPECTRA max 340 PC).

\section{Western Blot Analysis}

Western blot analysis for apoptosis, autophagy and signaling pathway regulated proteins. The relevant procedures have been previously described. ${ }^{3}$ Proteins were reacted with one of the followings: anti-LC3B (\#3868), anti-cleavaged Poly (ADP-ribose) Polymerase (cPARP) (\#5625) purchased from Cell Signaling (Danvers, MA), anti-p62 (GTX100685) obtained from GeneTex (Irvine, CA), or monoclonal anti- $\beta$ actin (Sigma, AC-40). Chloroquine (CQ, $10 \mu \mathrm{M})$ was added with DOC or VCR or VER in fresh medium for $48 \mathrm{hrs}$ treatment and cells were harvested for analysis.

\section{Annexin V Assay for Apoptosis Characterization}

Cells were trypsinized and incubated for 30 mins in binding buffer with propidium iodide (PI) and Annexin V (FITC Annexin V Apoptosis Detection Kit 1, BD Biosciences, San Jose, CA), followed by analysis with flow cytometry.

\section{Detection and Quantification of Acidic Vesicular Organelles (AVOs) for Autophagy Formation}

The detailed steps of AVO analysis have been previously described. $^{32}$ Briefly, after treatment, cells were washed with HBSS twice, followed by staining with acridine orange (1 g/mL, Sigma, A 6014). After staining, cells were washed with HBSS and suspended in HBSS containing 5\% FBS. The cells were observed under a red filter fluorescence microscope.

\section{Clonogenic Cell Proliferation Assay}

Cells were seeded in 6-well plates ( 150 cells/well). After 24 hrs of incubation, cells were treated with respective doses of CCBs, DOC or VCR for 48 hrs only and eventually cultured for 10 days with fresh medium. The colonies formed were fixed with ice-cold methanol for 30 mins then stained with $20 \%$ Giemsa. Survival fractions were calculated with microscope and normalization to appropriate control groups.

\section{Inhibition of ATG5 by VSV-G Pseudo Lentivirus-shRNA}

All RNAi reagents were obtained from the National RNAi Core Facility at the Institute of Molecular Biology/ Genomic Research Center, Academia Sinica. Individual clones were identified by their unique TRC number: shLuc TRCN0000072246 targeted to luciferase for vector control; clones of shATG5-394 (TRCN0000330394) and shATG5-474 (TRCN0000151474) targeted to ATG5. Lung cancer cells $\left(5 \times 10^{5} /\right.$ plate $)$ were seeded onto $60 \mathrm{~mm}$ plates and incubated at $37^{\circ} \mathrm{C}$ in Dulbecco's modified Eagle's medium supplemented with $10 \%$ fetal bovine serum, $1 \%$ non-essential amino acids solution, $1 \%$ sodium pyruvate, $1 \%$ L-glutamine, $100 \mathrm{IU}$ penicillin $\mathrm{mL}^{-1}$ and $100 \mathrm{mg}$ streptomycin $\mathrm{mL}^{-1}$ for $16 \mathrm{hrs}$. Then, cells were infected with lentivirus vectors at a multiplicity of infection of 1 . The next day, the cells were selected by $2 \mu \mathrm{g} / \mathrm{mL}$ 
puromycin (Sigma, P8833) with a fresh medium for 2 days. The stable cell lines of shLUC, shATG5-394 and shATG5-474 were used for drug treatment and analysis.

\section{Statistical Analysis}

All values are presented as mean \pm SD. Data were compared between groups using $t$-test and $* p<0.05$ was considered statistically significant.

\section{Results}

\section{Differential Effects of L-Type Calcium} Blockers on Chemoresistant Lung Cancer A549/D 16 Cells That Overexpressing P-gP

We have previously reported that A549/D16 cells are P-gp overexpressing chemoresistant lung cancer cells. ${ }^{3}$ When
A549/D16 cells were treated with VER for $48 \mathrm{hrs}$, the viability was not markedly reduced. In contrast, when A549/D16 cells were co-treated with VER and DOC, cytotoxicity was increased significantly on A549/D16 cells, reducing the survival of cells in a dose-dependent manner (Figure 1A). Interestingly, VER alone induces autophagy, also in a dosedependent manner, as shown by the increased levels of LC3BII, and co-treatment of VER/DOC preserved both autophagy induction and increased c-PARP production (Figure 1B). PARP cleavage has active roles in apoptosis. ${ }^{33}$ Surprisingly, large amounts of AVO formations were detected when VER/DOC was co-treated on A549/D16 cells (Figure 1C and Supplemental Figure 1). Although VER alone has little effect on viability (Figure 1A) and apoptosis (Figure 1B), the DOC-enhanced autophagy may upregulate apoptosis, as evidenced by increased c-PARP
A

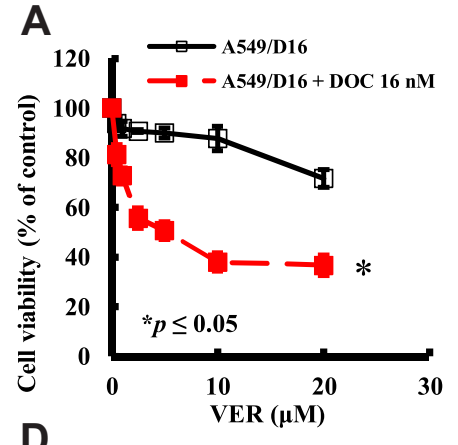

D

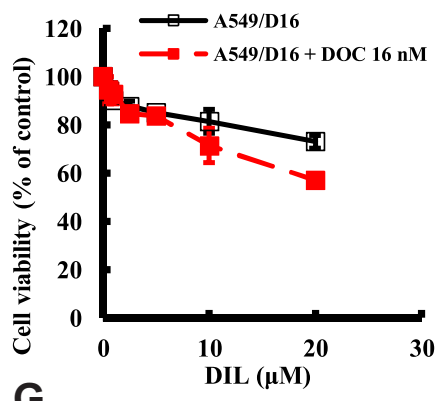

G

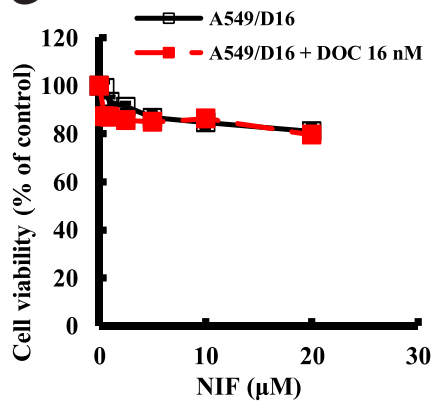

$B$

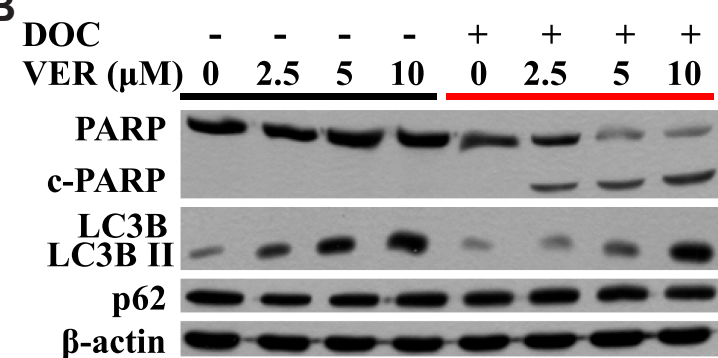

E

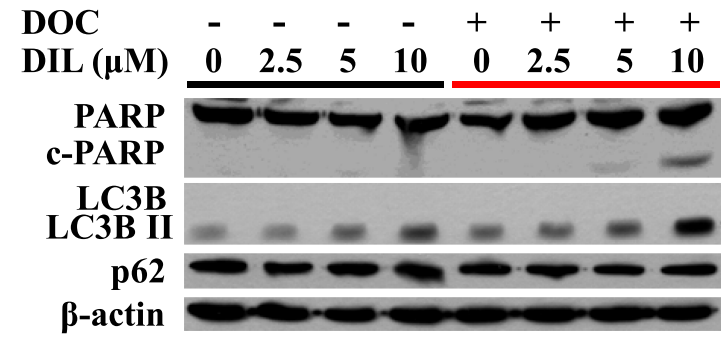

$\mathrm{H}$

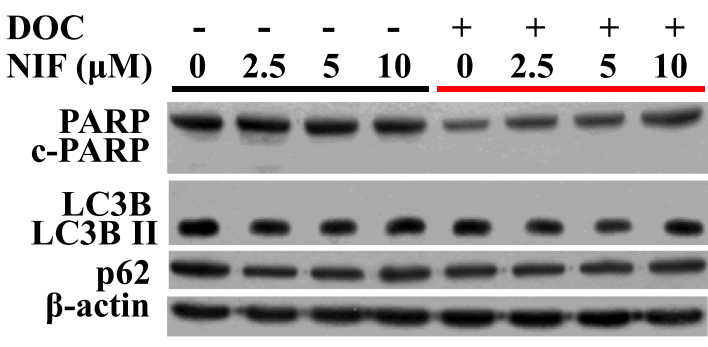

C
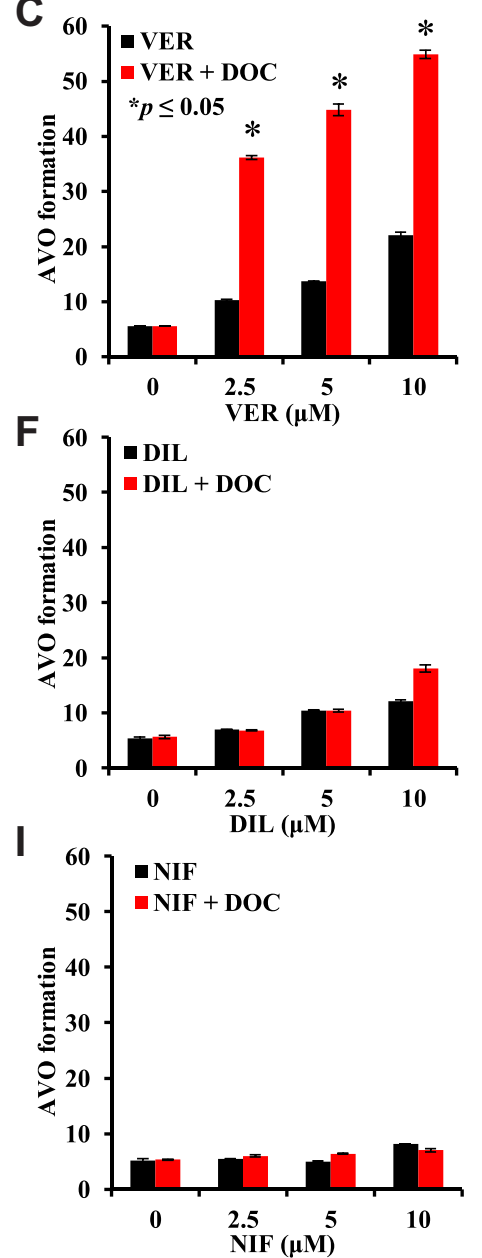

Figure I Investigation of the individual CCB-related sensitivity, apoptosis and autophagy in A549/DI6 cells with P-gP-overexpression. Viabilities of cells treated with (A) VER or VER combined with DOC (D) DIL or DIL combined with DOC (G) NIF or NIF/DOC analyzed by MTT assay. (B), (E) and (H) are Western blot analyses of the proteins of PARP and LC3B levels for apoptosis and autophagy. Analysis of AVO formation for autophagy when A549/DI6 cells treated with (C) VER or VER/DOC cotreatment, (F) DIL or DIL/DOC co-treatment, and (I) NIF or NIF/DOC co-treatment. * $<0.05$ was considered statistically significant. 
levels (Figure 1B). It is known the formation of LC3BII and significant breakdown of p62 indicate the initiation and completion of autophagic flux, ${ }^{34}$ but our data shown p62 expression was not reduced when LC3BII increased. A previous report has demonstrated that this phenomenon represents autophagosome accumulation and results in autophagic death in A549 cells. ${ }^{35}$ Thus, VER induces autophagy but not apoptosis, and strongly enhances DOC sensitivity on A549/D16 cells by excess autophagy and apoptosis.

The results shown in Figure 1D indicate that DIL plus DOC has less effect than VER combined with DOC for reducing A549/D16 cells survival (Figure 1A). DIL alone induces a moderate level of autophagy (Figure $1 \mathrm{E}$ and F) and only a high dose $(10 \mu \mathrm{M})$ of DIL combined with DOC induces apoptosis, as indicated by increased c-PARP (Figure 1E). When combined with DOC, DIL moderately upregulates autophagy (Figure 1F and Supplemental Figure 1).

The results of Figure $1 \mathrm{G}$ and $\mathrm{H}$ indicate that NIF alone or combined with DOC has no effect on A549/D16 cell viability, and only background level of AVO formation was detected (Figure 1I and Supplemental Figure 1).

\section{Effects of CBCs on P-gp Independent Chemoresistant A549/VI6 Lung Cancer Cells}

The effects of VER on A549/V16 cells were very similar to VER on A549/D16 cells, indicating that VER co-treatment with VCR sensitized A549/V16 cells to death (Figure 2A and B). Apoptotic A549/V16 cells (Figure 2B) were also associated with a high level of autophagy when VER was combined with VCR (Figure 2B, C and Supplemental Figure 2).

When A549/V16 cells were treated with DIL, cell survival was downregulated (Figure 2D) with steady levels of autophagy (Figure 2F). Only when DIL was combined with VCR, autophagy levels were significantly increased (Figure 2F and Supplemental Figure 2), but only minimal c-PARP proteins were detected under the same conditions (Figure 2E). The results demonstrate that DIL and VCR sensitized A549/V16 cells to death less effectively than VER combined with VCR (Figure 2A and B). These results indicate that in addition to apoptosis, an autophagy burst with VER/DOC- or VER/VCR-induced autophagosome accumulation may lead to the death of chemoresistant lung cancer cells.

NIF alone has little effect on the sensitivity of A549/ V16 cells (Figure 2G) and has little effect on autophagy
(Figure 2H and I). When A549/V16 cells were treated with NIF combined with VCR, although cell survival has been reduced (Figure 2G), apoptotic markers of c-PARP were not detected (Figure $2 \mathrm{H}$ ) and AVO formation did not increase significantly (Figure 2I and Supplemental Figure 2).

\section{Anti-Proliferation Effects of CCBs Analyzed by Clonogenic Cell Survival Assay}

To characterize the long-term effect of individual CCB on chemoresistant A549 sublines proliferation, the cells were divided into two sets, treated for $48 \mathrm{hrs}$ with either CCB alone or CCB combined with DOC or VCR. Then, cells were feeded with fresh medium and incubated for 10 days, the numbers of colonies were counted as shown in Figure 3. For the A549/D16 cells treated with VER (Figure 3A) or DIL alone (Figure $3 \mathrm{~B}$ ), the numbers of colonies were not higher than cells without CCB ( 0 , VER or DIL). In contrast, there were more colonies in NIF-treated A549/D16 cells (Figure 3C). For the A549/D16 cells treated with individual CCB combined with DOC, VER $(2.5 \mu \mathrm{M})$ strongly enhances DOC toxicity and reduces colony numbers (Figure $3 \mathrm{~A}$ ), and DIL $(5 \mu \mathrm{M})$ moderately enhances DOC toxicity (Figure 3B). NIF $(10 \mu \mathrm{M})$ has less effect on reversing DOC resistance when combined with DOC on A549/D16 cells (Figure 3C). For A549/V16 cells treated with VER alone, more colonies were detected (Figure 3D). DIL (Figure 3E) and NIF alone (Figure 3F) have little effect on survival of A549/V16 cells. When CCB was combined with VCR, VER significantly sensitized VCR-resistant cells resulting in fewer colonies (Figure 3D). DIL moderately enhances DOC toxicity (Figure 3E) and NIF has little effect on enhancing VER toxicity on A549/V16 cells (Figure 3F). The results of MTT assay showed CCBs by themselves may repress proliferation of chemoresistant cells (Figures 1 and 2) but similar data were not obtained from the clonogenic assay. The difference may result from those cells only treated with $\mathrm{CCBs}$ for $48 \mathrm{hrs}$ but not continuously exposed to CCBs in the clonogenic assay. These results indicate that $\mathrm{CCB}$ medication with chemotherapy suppresses the proliferation of chemoresistant lung cancer cells.

\section{Individual CCB-Sensitizing DOC/VCR Chemotherapy on Chemoresistant} Sublines with Different Efficacy

To further analyze the anticancer effect of CCBs on chemotherapy, the growth kinetics of A549/D16 cell was 

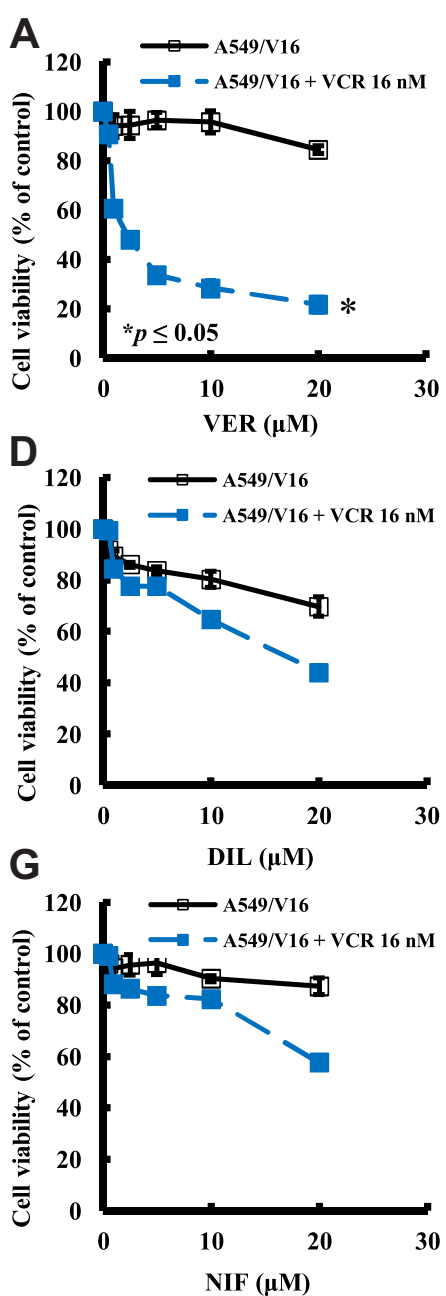

B

\begin{tabular}{lcccccccc} 
VCR & - & - & - & - & + & + & + & + \\
$\operatorname{VER}(\mu M)$ & 0 & 2.5 & 5 & 10 & 0 & 2.5 & 5 & 10 \\
\hline
\end{tabular}

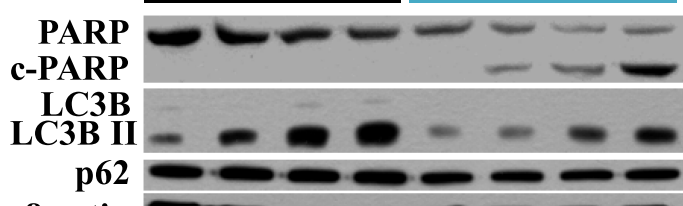

$\beta$-actin

E

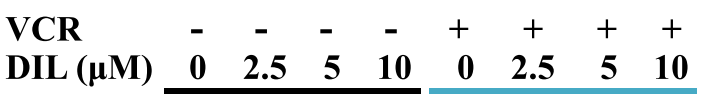

\begin{tabular}{lllllllll} 
DIL $(\mu M)$ & 0 & 2.5 & 5 & 10 & 0 & 2.5 & 5 & 10 \\
\hline
\end{tabular}

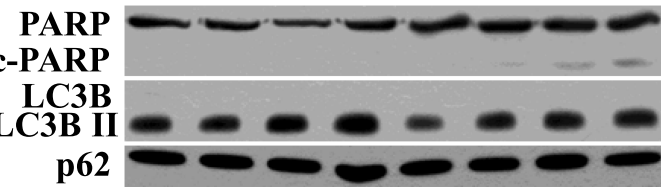

$\beta$-actin

H
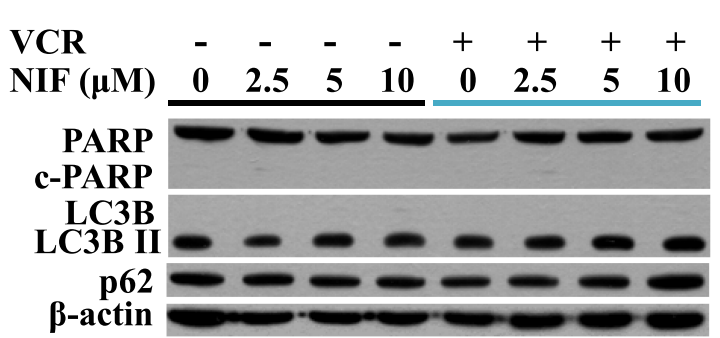

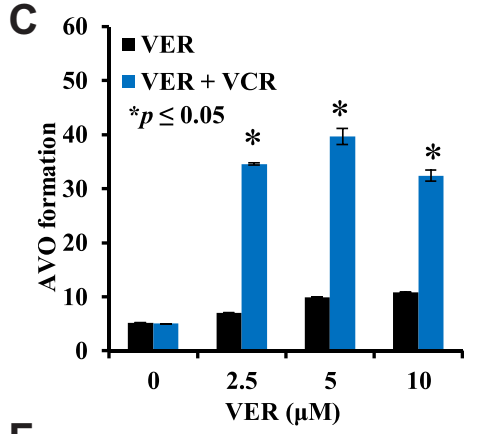

F
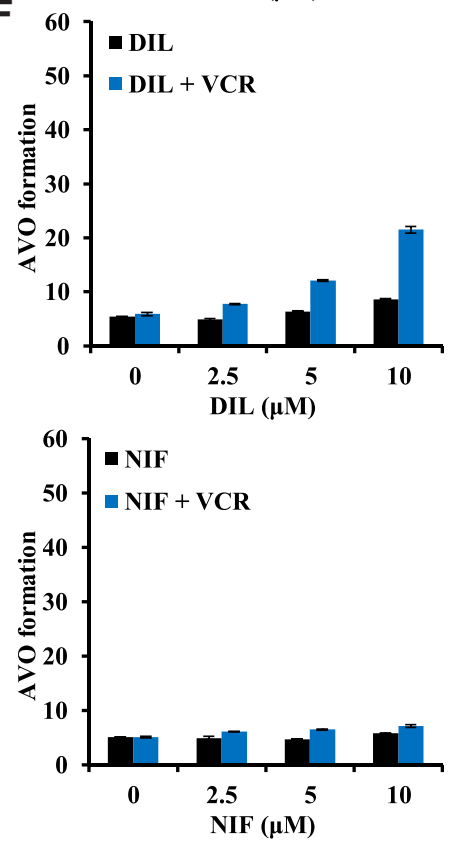

Figure 2 Investigation of the individual CCB-related sensitivity, apoptosis and autophagy in A549/VI6 chemoresistant cells lacking P-gP-overexpression. Viabilities of cells treated with (A) VER or VER combined with VCR (D) DIL or DIL combined with VCR (G) NIF or NIF/VCR analyzed by MTT assay. (B), (E), and (H) are Western blot analyses of the proteins of PARP and LC3B levels for apoptosis and autophagy. Analysis of AVO formation for autophagy when A549/VI6 cells treated with (C) VER or VER/ VCR co-treatment, (F) DIL or DIL/VCR co-treatment, and (I) NIF or NIF/VCR co-treatment. * $\mathrm{p}<0.05$ was considered statistically significant.

compared in three different groups. The first group compared chemoresistant A549/D16 cells treated with DOC $(16 \mathrm{nM})$ to blank control cells, the second group compared cells treated with CCB $(5 \mu \mathrm{M})$ only with cells treated with CCB $(5 \mu \mathrm{M})$ combined with DOC $(16 \mathrm{nM})$. The third group compared cells treated with $\mathrm{CCB}(10 \mu \mathrm{M})$ with cells treated with CCB $(10 \mu \mathrm{M})$ and DOC $(16 \mathrm{nM})$. The data were analyzed by MTT assay for three-day periods (Figure 4A). Similar conditions for the A549/V16 subline were also studied (Figure 4B). Results obtained from the group-1 demonstrate that these two sublines were resistant to $\mathrm{DOC}$ or VCR, and that they have no response to chemotherapy with a high dose of cytotoxic DOC or VCR. Groups 2 and 3 show growth inhibition effects of individual CCB on A549 sublines with dose-responsiveness. Clearly, VER is a better candidate to suppress chemoresistance than DIL and NIF for both A549/D16 and A549/V16 cells when combined with chemotherapy.

\section{Pan-Caspase Inhibitor Z-VAD-FMK Reduces VER/DOC-Induced Cell Death with Persistent Autophagy}

The associations of apoptosis in CCB and chemotherapyinduced chemoresistant lung cancer cell death were further investigated by applying the pan-caspase inhibitor (Z$\mathrm{VAD}, 50 \mu \mathrm{M}$ ) followed by Annexin $\mathrm{V}$ assay of flow cytometry (Figure 5A and B) and Western blot analysis (Figure $5 \mathrm{C}$ and $\mathrm{D}$ ). Pre-treatment of $\mathrm{Z}-\mathrm{VAD}$, significantly reduced the VER/DOC- or VER/VCR-induced death of A549 sublines (Figure 5A and B, respectively). At the same time, the levels of cleavage product of PARP were reduced by Z-VAD but LC3BII remained at higher levels 
A

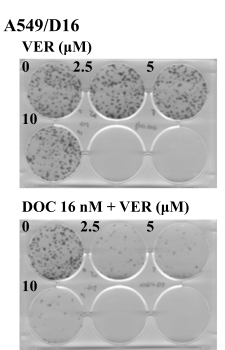

D

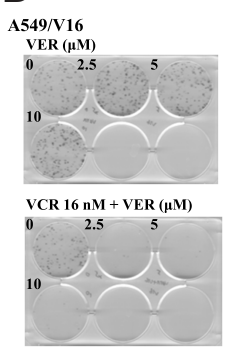

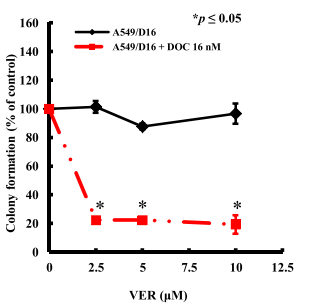

VER $(\mu \mathrm{M})$

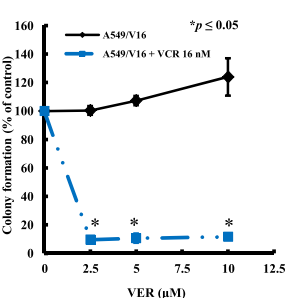

B

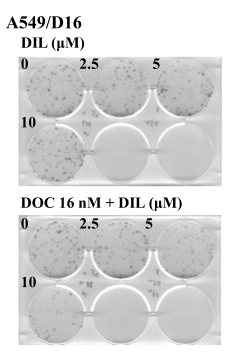

E

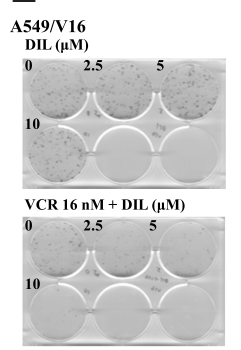

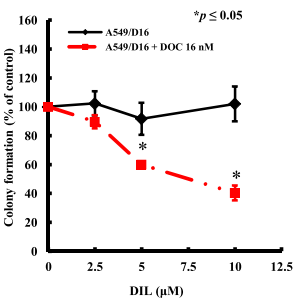

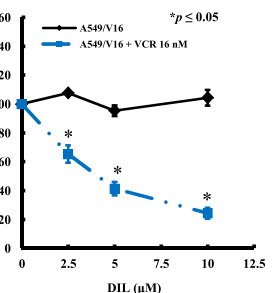

C
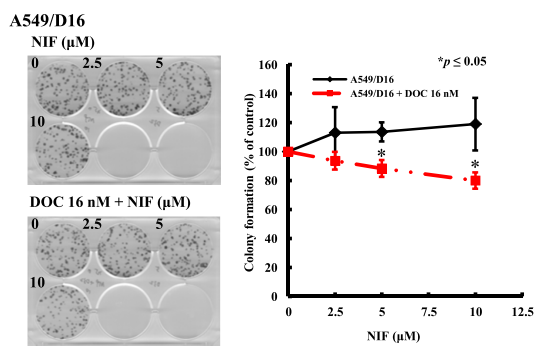

$\mathbf{F}$
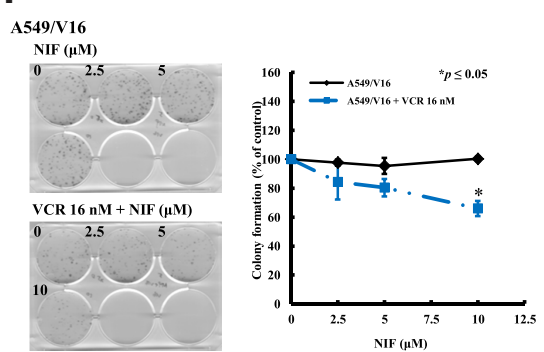

Figure 3 Antiproliferation effect of CCBs on A549 chemoresistant sublines analyzed by colony formation assay. A549/DI6 and A549/VI6 sublines were treated with VER (A, D), DIL (B, E), and NIF (C, F) alone, respectively, or co-treated with DOC (A, B, and C) or VCR (D, E, and F) for 48 hrs and incubated with fresh medium for 10 days and the colonies were calculated. The data were collected and normalized to the control set that without CCBs. * $<<0.05$ was considered statistically significant.

in response to $\mathrm{VER} / \mathrm{DOC}$ or $\mathrm{VER} / \mathrm{VCR}$ treatment (Figure 5C and D, respectively). Therefore, VER/DOCor VER/VCR-induced autophagy were not been affected when caspase-dependent apoptosis was blocked. The data indicate that CCB- and chemotherapy-induced chemoresistant lung cancer cell death is associated with caspasedependent apoptosis.

\section{Autophagy Inhibition by shATG5 Also Reduces VER/DOC-Induced Cell Death and Represses Caspases Activation}

To investigate the role of CCB-induced autophagy in the death of chemoresistant lung cancer cells, we induced shRNA interference by introducing two individual clones of shATG5-394 and shATG5-474 to reduce ATG5 expression in A549/D16 cells that can block the autophagosome formation. ${ }^{36}$ The effect of autophagy inhibition on cell apoptosis was analyzed by Annexin $\mathrm{V}$ assay of flow cytometry (Figure 6A). After autophagy inhibition, VER/DOC combinations have less cell death than the shLUC control. Compared with the shLUC infection control, shATG5-394, and shATG5-474 significantly reduced ATG5 expression, resulting in LC3B-II down-regulation without VER treatment. When VER was combined with DOC, shATG5-394 infected cells still lacked LC3B-II expression corresponding to autophagy inhibition
(Figure 6B). Similar responses were also observed when a clone of shATG5-474 was used. The c-PARP levels were also reduced when autophagy was inhibited. These results indicate a pro-death role for VER/chemotherapyinduced autophagy.

\section{Chloroquine Blocks Autophagic Flux and Enhance Caspase-Independent Cell Death} Chloroquine (CQ), which is an inhibitor of autophagy that blocks the binding of autophagosomes to lysosomes. ${ }^{37}$ To address the VER/chemotherapy mediated autophagy burst resulted in cell death, CQ $(10 \mu \mathrm{M})$ was added with DOC or combined with DOC/VCR to treat the cells. The data obtained from Annexin V assay without CQ and only with DOC was $8.99 \pm 0.57$ of total apoptotic cells that versus $36.81 \pm 1.17$ when CQ was added. Increased c-PARP and LC3BII levels were detected (Figure 6E left panel) when CQ co-treated with DOC. The data suggest that CQ treatment associated with apoptosis and autophagy. In the present of VER $(10 \mu \mathrm{M}), \mathrm{CQ}$ and DOC, more annexin V positive cells were detected $(89.10 \pm 2.19)$ that reflecting large amount of cell death was occurred (Figure 6C). Although CQ augment LCBII level; reduced c-PARP expression on cells that treated with CQ, VER $(10 \mu \mathrm{M})$ and DOC when compared with VER $(10 \mu \mathrm{M})$ and DOC treatment (Figure 6E left panel). The expression of p62 
A
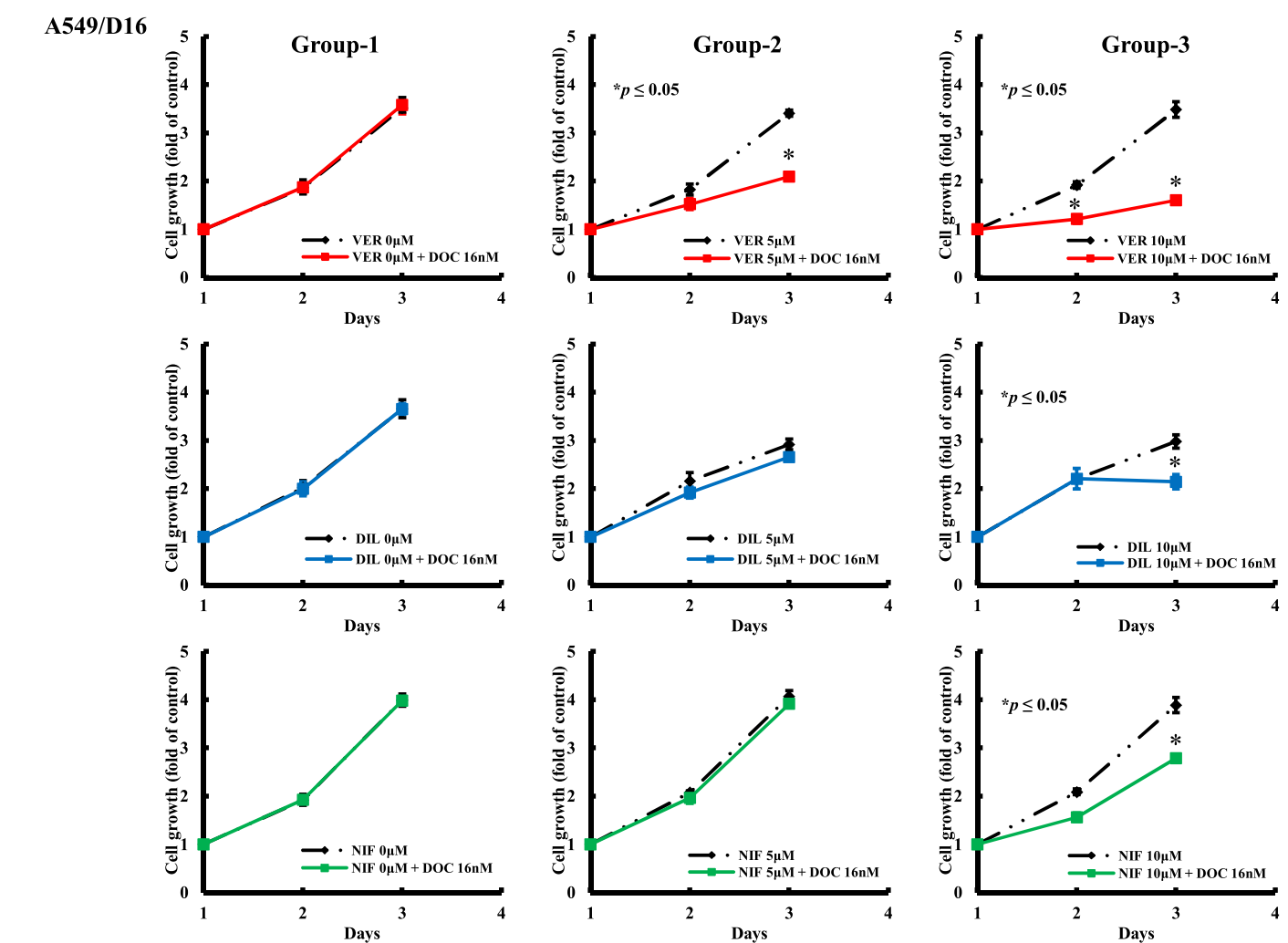

B
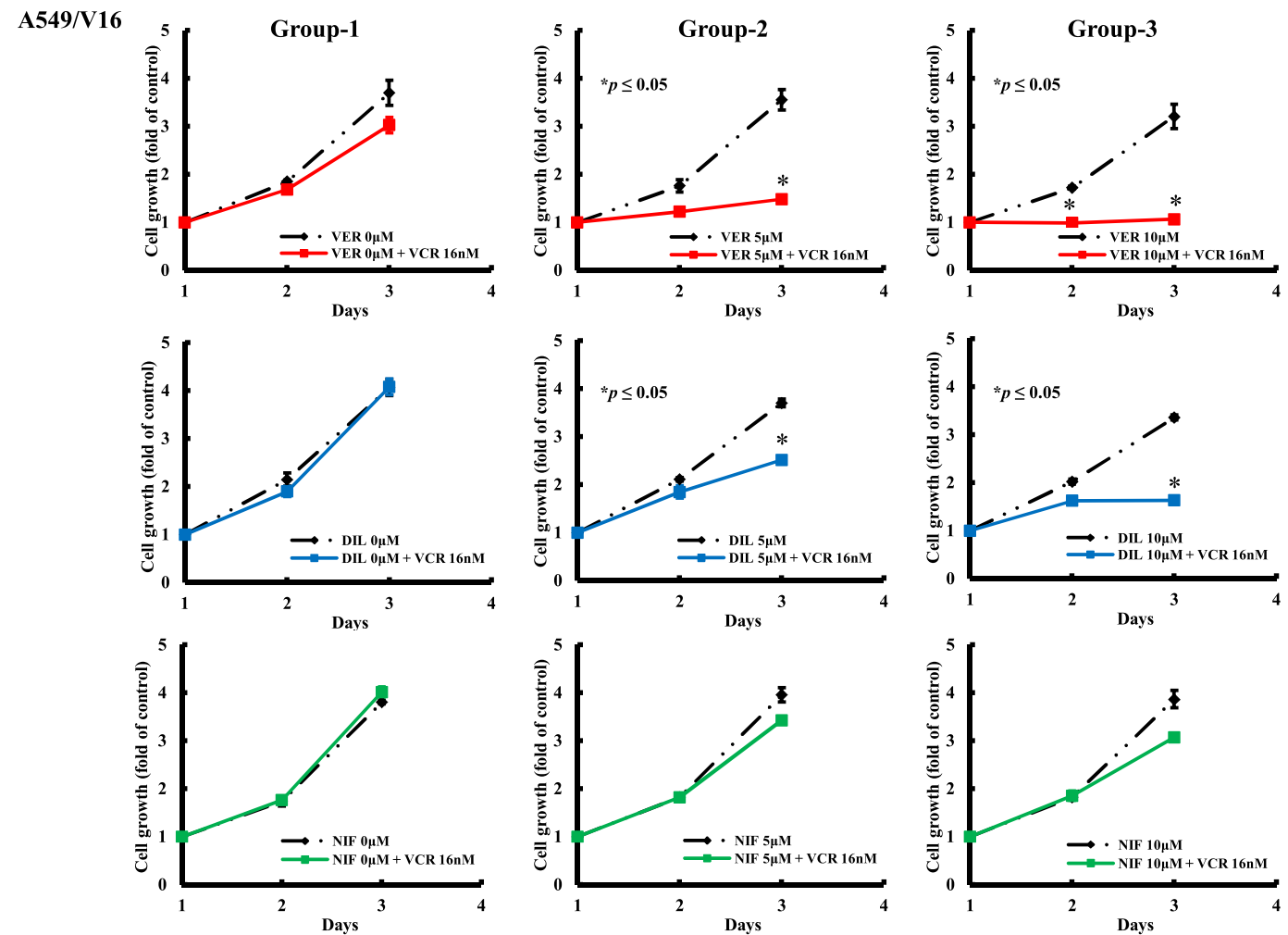

Figure 4 Analysis of the growth inhibition effect of individual CCBs on A549 chemoresistant sublines analyzed by MTT assay. Group-I compared chemoresistant A549/D I6 cells $(\mathbf{A})$ treated with DOC $(16 \mathrm{nM})$ to blank control cells, and group- 2 compared cells treated with $\mathrm{CCB}(5 \mu \mathrm{M})$ only with cells treated with CCB (5 $\mu \mathrm{M})$ combined with DOC (16 nM). Group-3 compared cells treated with CCB $(10 \mu \mathrm{M})$ with cells treated with CCB $(10 \mu M)$ and DOC (16 nM). The data were analyzed by MTT assay for threeday periods. Similar conditions for A549/VI6 subline were applied and studied (B). ${ }^{*} p<0.05$ was considered statistically significant. 
A

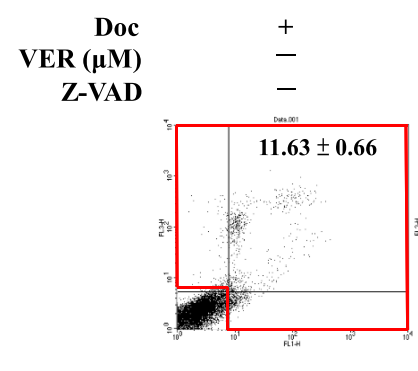

Doc
VER $(\boldsymbol{\mu M})$
$Z$-VAD

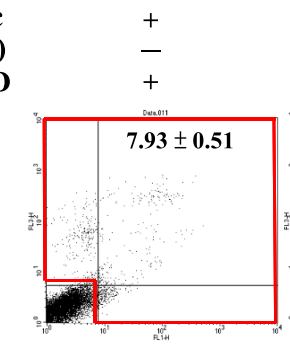

A549/D16
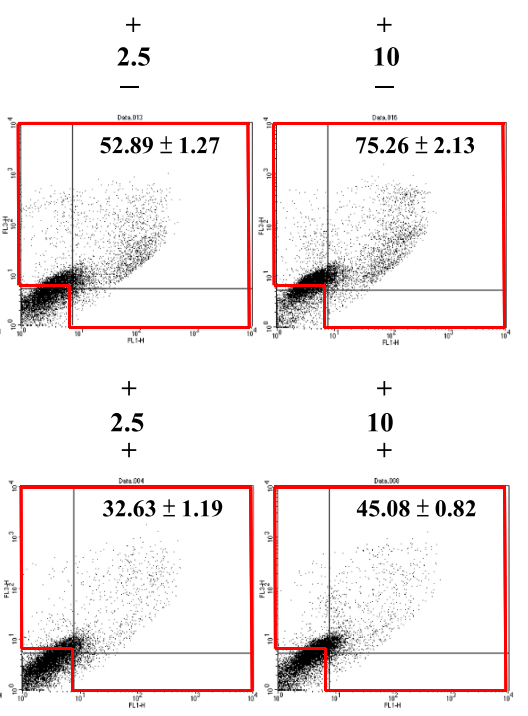

A549/V16

B

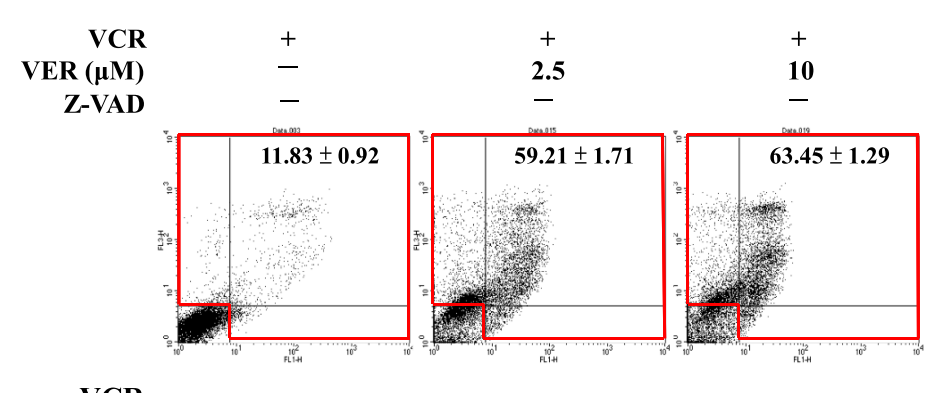

VCR

VER $(\mu \mathrm{M})$
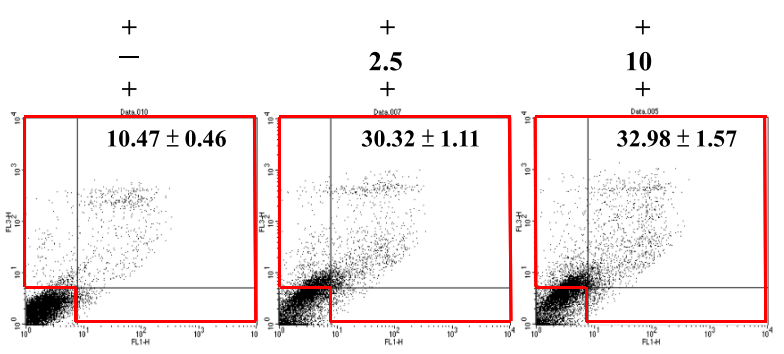

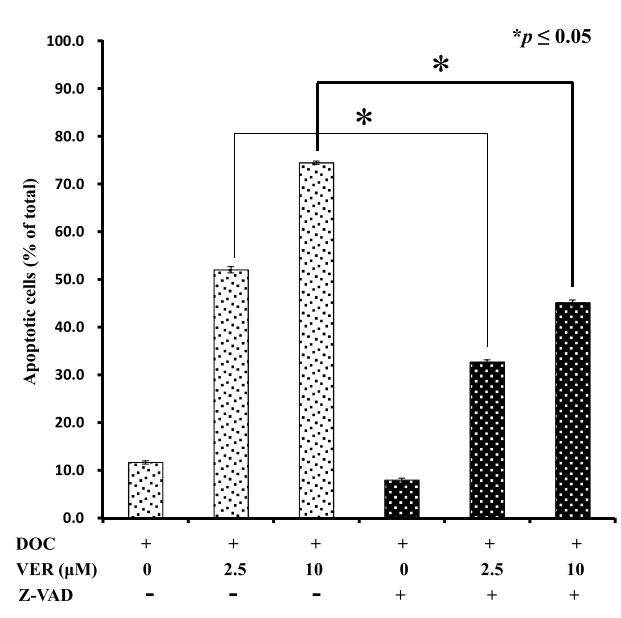

C

A549/D16

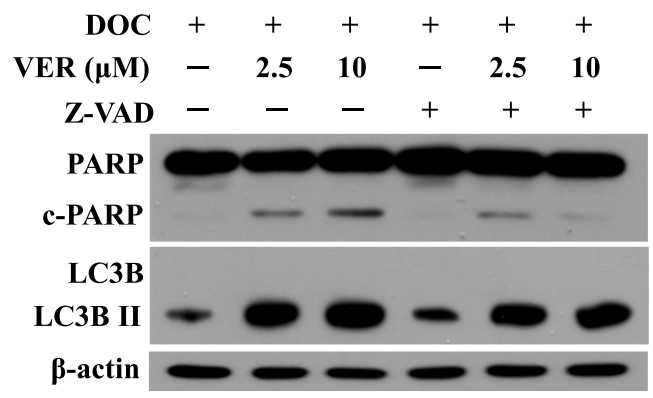

D

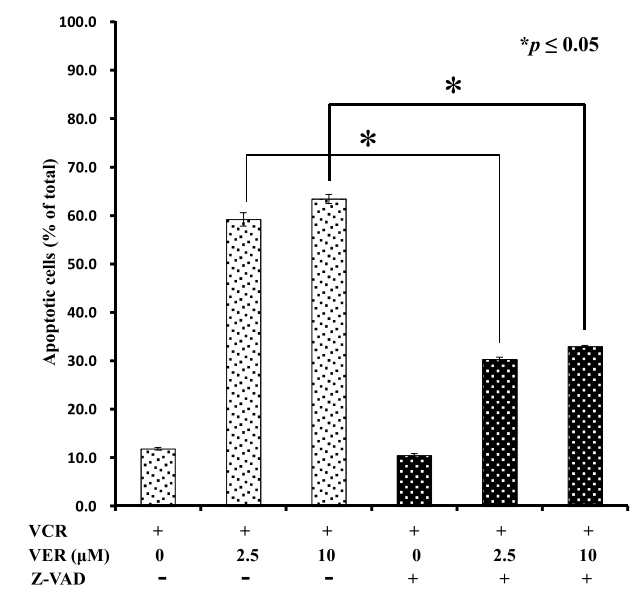

A549/V16

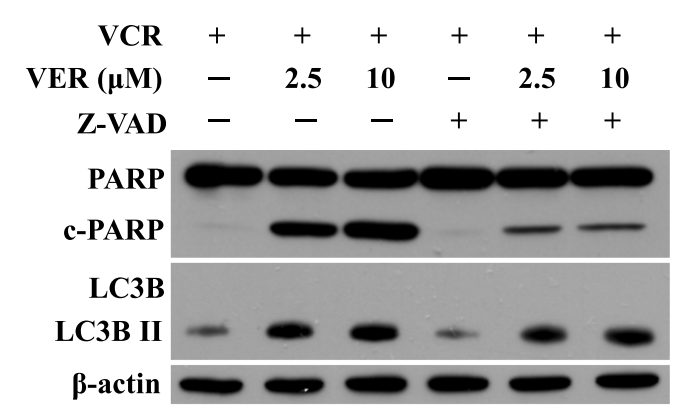

Figure 5 Effects of caspases inhibition on VER/DOC- and VER/VCR-induced apoptosis and autophagy. (A) Pre-treatment of pan-caspase inhibitor (Z-VAD, $50 \mu M)$ for I hr followed by VER/DOC or (B) VER/VCR co-treatment for 48 hrs and analyzed by Annexin V assay of flow cytometry on A549/DI6 and A549/VI6 cells, respectively. (C and D) Expressions of PARP, cPARP LC3B and LC3B-II were detected by Western blot analysis with the same treatment conditions as $(\mathbf{A}$ and $\mathbf{B})$. * $p<0.05$ was considered statistically significant. 


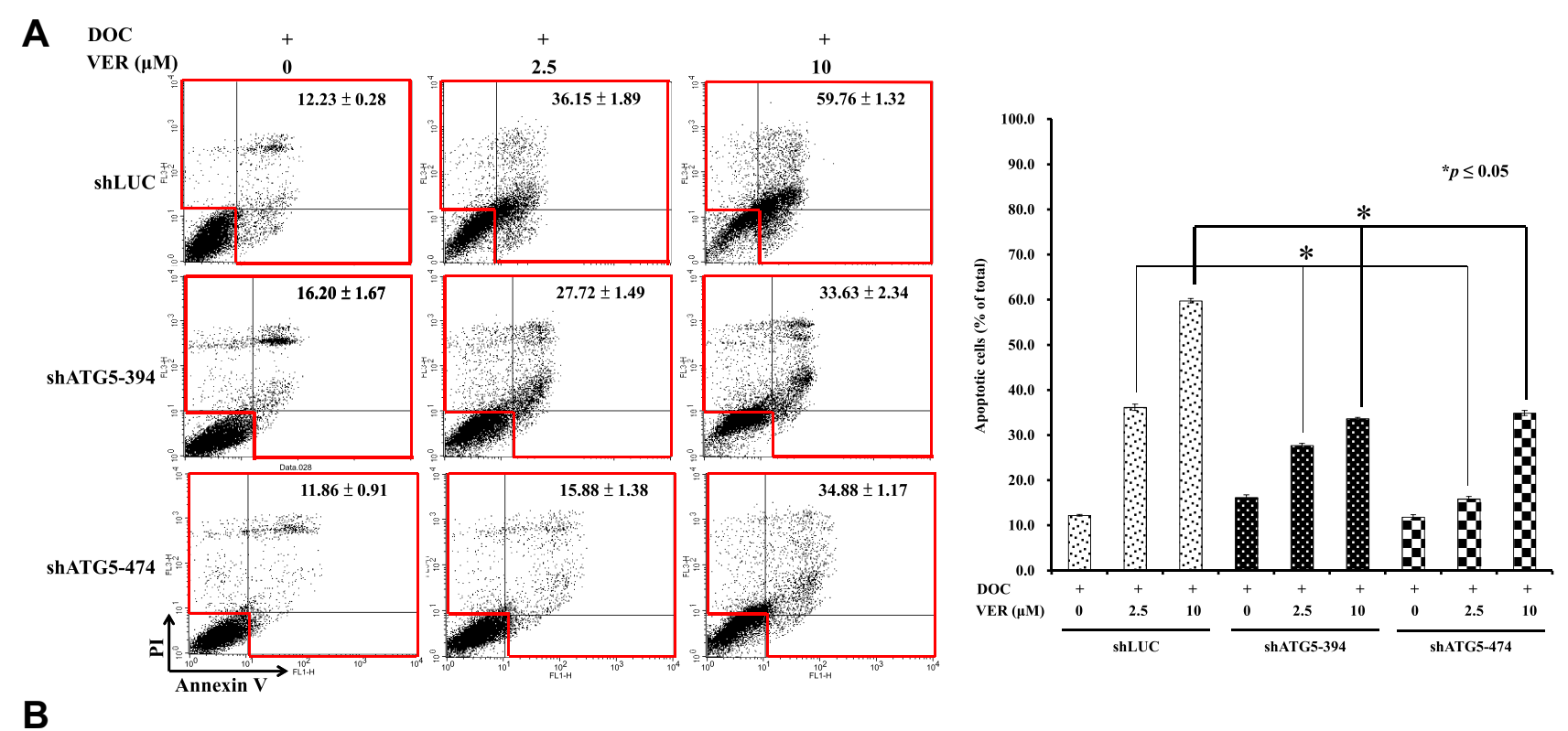

A549/D16

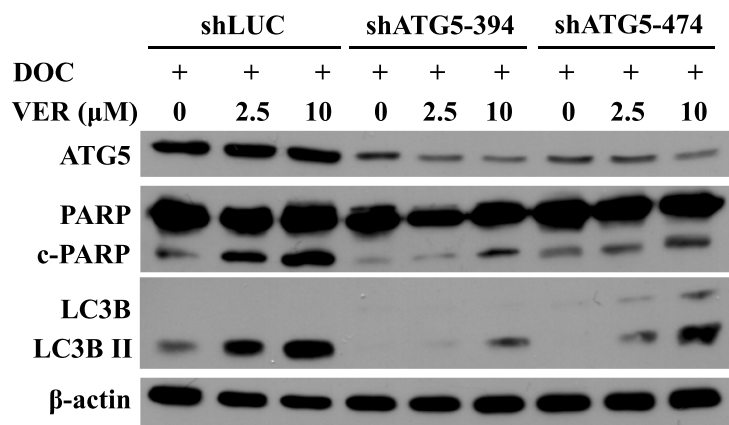

C A549/D16
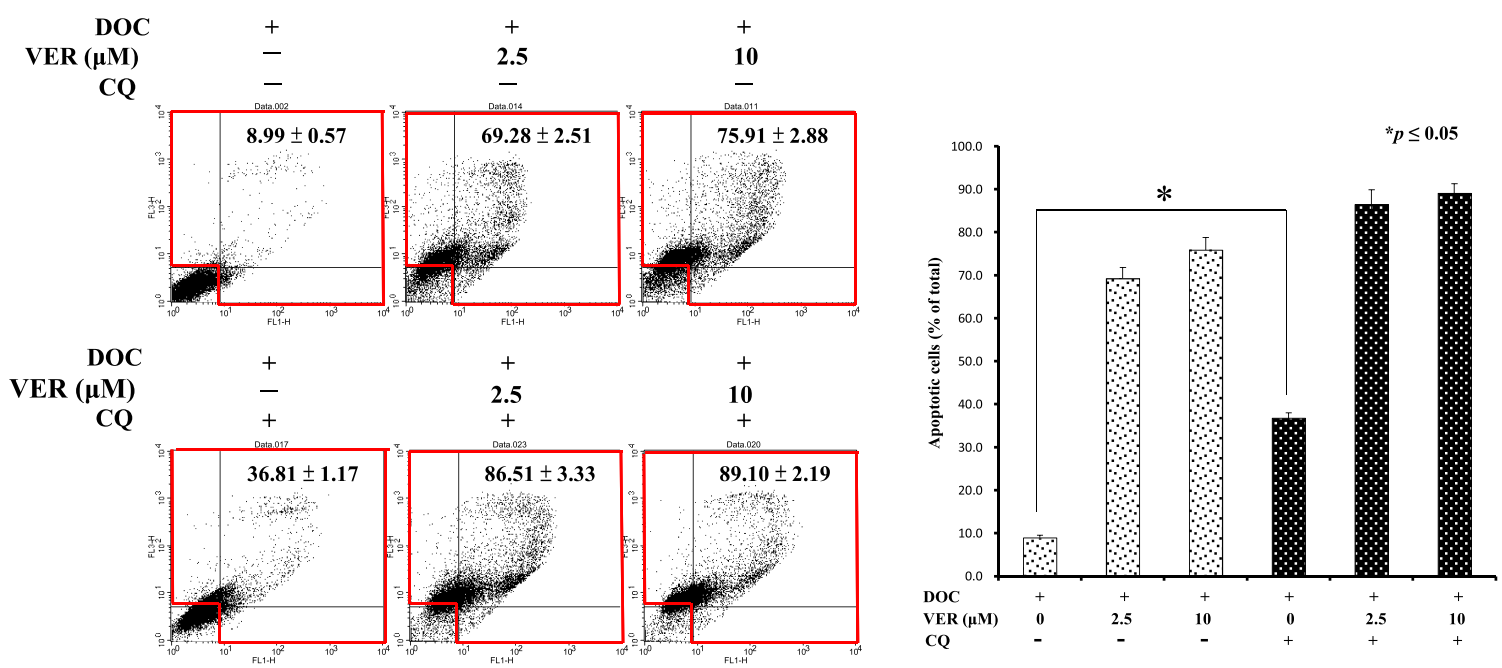

Figure 6 Continued.

was not significantly decreased in Figure 6E. Similar results were also obtained from the A549/V16 cells that investigated with same conditions (Figure 6D). These results support that CQ block autophagic flux and enhance VER/chemotherapy-induced autophagy burst that resulted in caspase-independent cell death. 
D

A549/V16
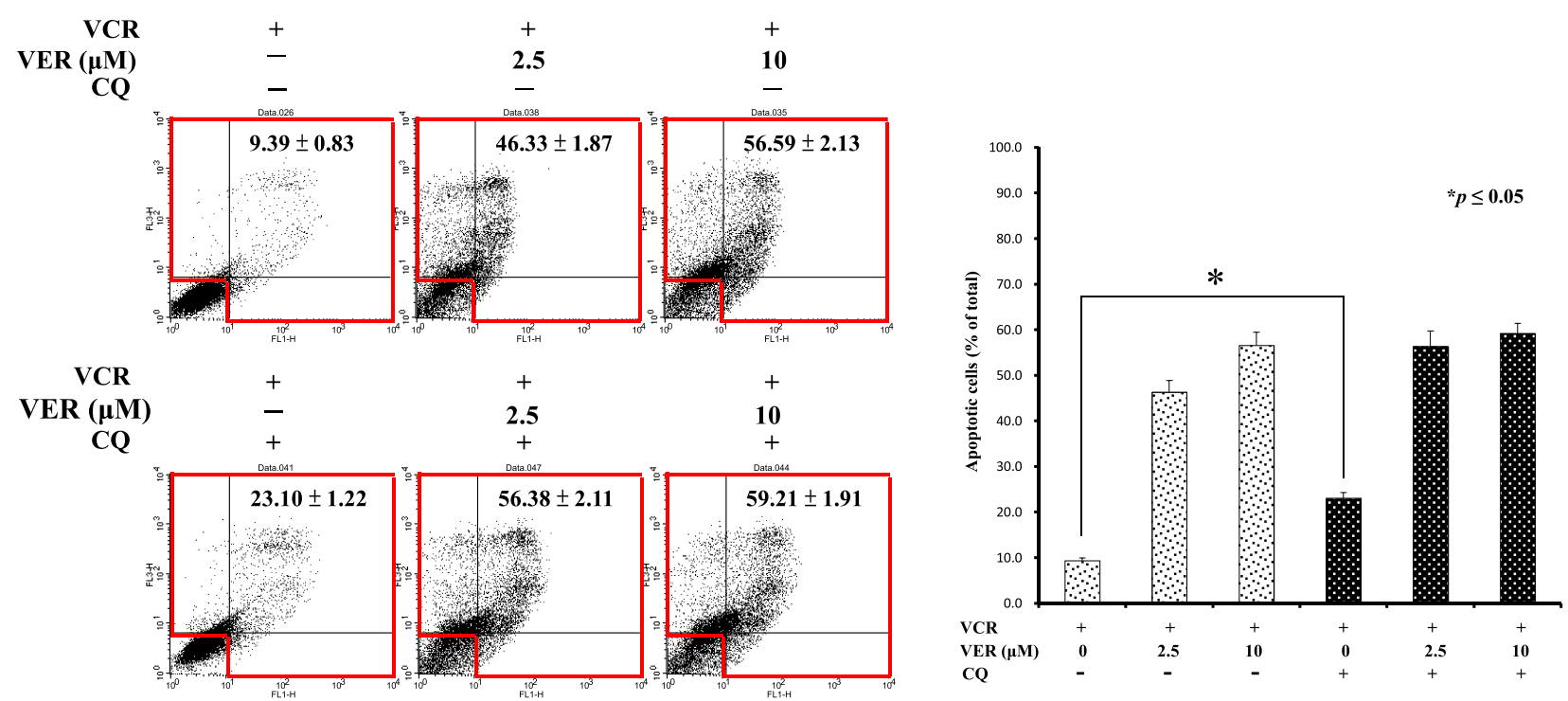

$\mathbf{E}$

A549/D16

A549/V16
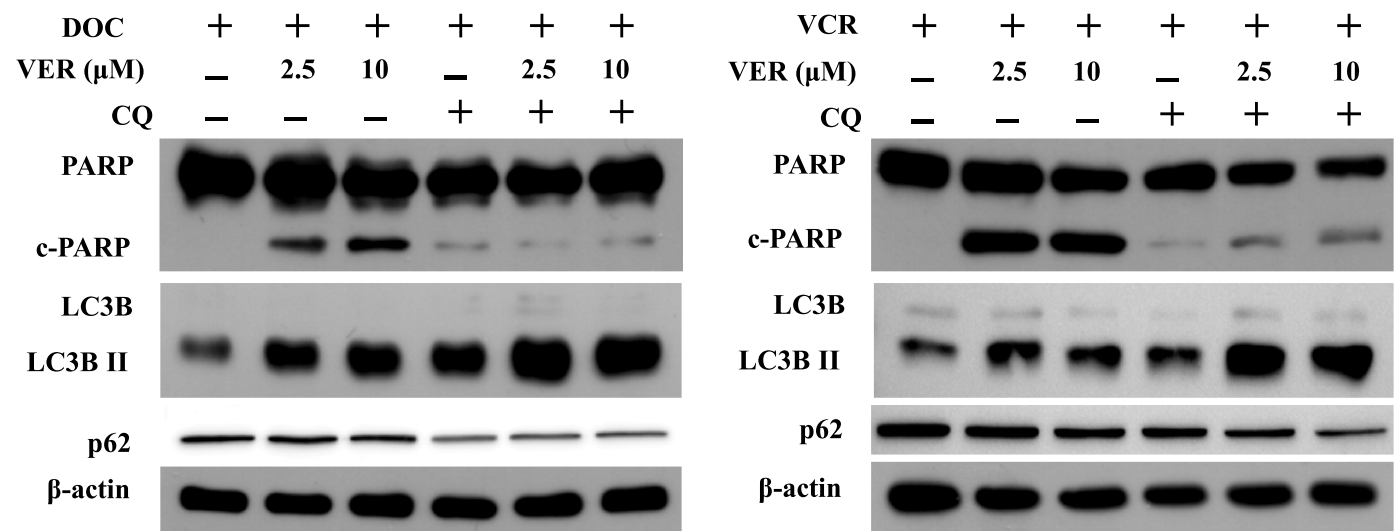

Figure 6 Effects of autophagy inhibition by shATG5 infection and chloroquine on VER/DOC-induced apoptosis and autophagy. (A) Individual shATG5-394 and shATG5-474 were used to inhibit ATG5 protein expression with shLUC as the infection control. Collected cells were further analyzed by Annexin $V$ assay of flow cytometry on A549/ DI6 cells in the presence of DOC $(16 \mathrm{nM})$ with or without VER for $48 \mathrm{hrs}$, followed by (B) Western blot analysis of protein obtained under same experimental conditions. (C) Chloroquine (CQ, $10 \mu \mathrm{M}$ ) was combined with DOC or DOC/VER (D) CQ was combined with VCR or VCR/VER to treat the cells for 48 hrs and analyzed by Annexin V assay of flow cytometry on A549/D I6 and A549/VI 6 cells, respectively. (E) Proteins obtained under the same experimental conditions were analyzed by Western blot assay. $*_{p}<0.05$ was considered statistically significant.

\section{A Proposed Model for CCBs and Chemotherapy-Induced Cell Death on Chemoresistant Lung Cancer Cell}

We have tested the anticancer effect of DHP (NIF) and Non-DHP (VER, DIL) with chemotherapy on chemoresistant lung cancer cells (Figure 7). The caspase dependent cell death is associated with anticancer effect of Non-DHP type CCBs. Autophagy induced by CCBs/chemotherapy (autophagy burst) plays a pro-death role that were supported by (1) the shATG5 knockdown that reduced autophagy and cell death; (2) CQ blocks autolysosome formation and enhances VER/chemotherapy-induced autophagy burst and resulted in caspase independent cell death. Verapamil combined with chemotherapy provides more strongly anticancer effect than Diltiazem, and Nifedipine, respectively.

\section{Discussion}

Hypertension is known to have significant effects on cardiovascular (CVD) outcomes, which is the leading cause of death and disability in the world. ${ }^{38}$ In 2012-2013, the prevalence of hypertension in Canadian adults was $22.6 \%$, an increase from $19.6 \%$ in $2009-2011 .^{39}$ It is associated 


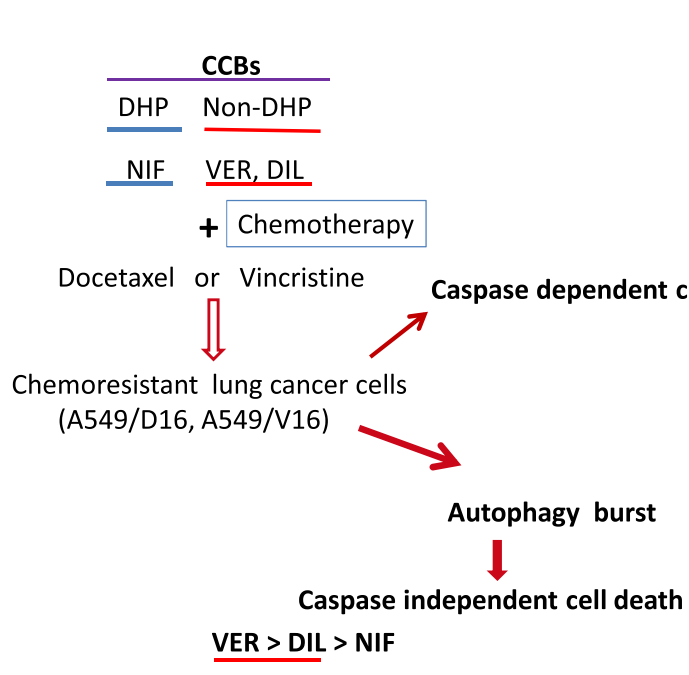

Anti-cancer activity of CCBs + chemotherapy
Autophagy inhibition by shATG5 reduces autophagosome formation and reduces caspase dependent cell death

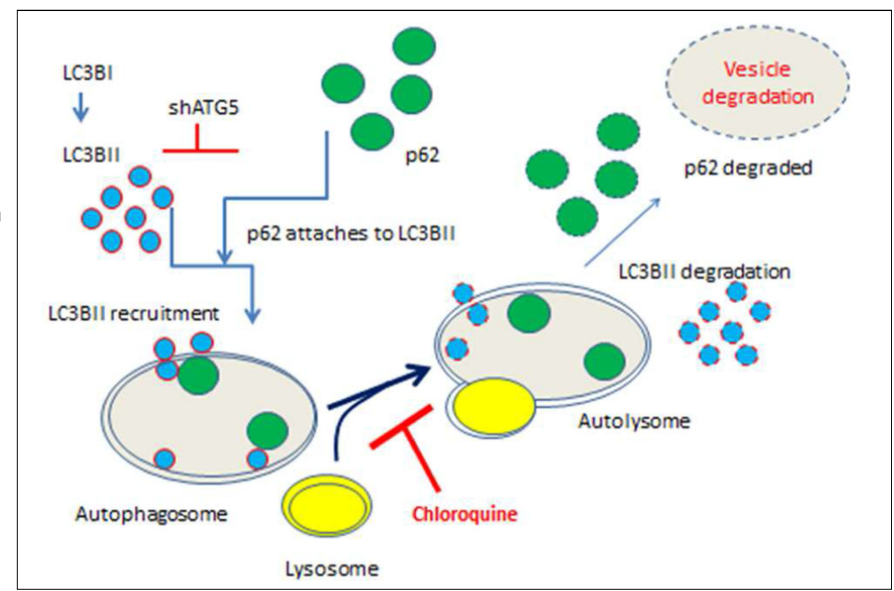

Autophagy inhibition by chloroquine increases autophagosome formation and increases caspase-independent cell death

Figure $7 \mathrm{~A}$ proposed model of anticancer effects using CCBs combined with chemotherapy to induce cell death on chemoresistant lung cancer cells. Administration of VER or DIL induces autophagy; and death ratios of chemoresistant cells were significantly increased when VER combined with chemotherapy. Both caspase-dependent and independent cell death mechanisms contribute to the anticancer effects of VER/chemotherapy. Knockdown of ATG5 by shATG5 reduced caspase-dependent cell death. Whereas, accumulation of autophagosomes by VER/chemotherapy or CQ results in cells to be burst in a caspase-independent pathway of cell death.

with 7.6 million premature deaths (about $13.5 \%$ of the global total) per year worldwide, making it the leading risk factor for cardiovascular disease (CVD) ${ }^{40}$ In Europe, hypertension is one of the most common causes of primary care interventions, and CCBs are a first-line treatment for this symptom. ${ }^{41}$ There has, however, been a long debate regarding the potential association of $\mathrm{CCBs}$ with increased cancer risk, especially for breast cancer. ${ }^{42-44}$ Several studies and randomized controlled trials suggest a positive association of $\mathrm{CCBs}$ with breast cancer incidence. ${ }^{45,46}$ There has been little research on the possible effects of CCBs on cancer survival. It was reported that there had no evidence that $\mathrm{CCB}$ use was associated with a better or worse survival in cancer patients in Asian and Caucasian populations. ${ }^{47}$ On the contrary, association of $\mathrm{CCB}$ use with risks of breast cancer outcomes has also been reported, ${ }^{48}$ and CCBs have been associated with increased cancer recurrence in patients with head and neck squamous cell carcinoma. ${ }^{49} \mathrm{CCBs}$ also have been associated with decreased survival in certain cancers when compared with $\beta$-blockers. ${ }^{50}$ Deaths were also increased with CCBs use in patients with breast cancer; in contrast, $\mathrm{CCBs}$ use was associated with improved survival in lung cancer patients. ${ }^{25}$ To resolve this discrepancy in lung cancer and breast cancer outcomes, this study demonstrates the potential mechanisms of CCB association with improved survival in lung cancer patients.
We show that VER and DIL alone can induce autophagy and co-treatment with DOC or VCR, further enhancing autophagy and apoptosis in typical-MDR A549/D16 and atypical-MDR A549/V16 chemoresistant lung cancer cells. Therefore, the anticancer activities of individual CCBs are not affected by P-gp expression. In contrast, NIF is a member of DHP-group CCBs, and NIF alone or combined with chemotherapy has little anticancer effect. We also address that autophagy induced by CCBs is a prodeath response in chemoresistant lung cancer A549 cells. In the present of chemotherapy, VER further enhance autophagosome formation but not vesicle degradation. The protein of p62 should be efficiently degraded by autophagy, ${ }^{51}$ therefore, autophagic flux suppression should correlate with an increased p62 level. Logically, CQ is an autophagy flux blocker that should enhance p62 level. Surprisingly, the expression of p62 was not significantly increased in Figure 6E. It has been reported that p62 is degraded by both the autophagy and ubiquitin-proteasome system, ${ }^{52}$ It is possible that when autophagosomes were accumulated and ready to be burst, p62 can be degraded by proteasome when cells were overwhelmed with death stress. It is presently unclear how VER/Chemotherapy suppress autophagic flux and resulted in autophagy burst.

In contrast to our findings, VER-induced cytoprotective autophagy has been found in a series of human cell lines, including colon adenocarcinoma COLO 205 cells, 
prostate cancer PC-3 cells and prostate PNT-2 cells, pancreatic cancer KP-4 cells, and pancreatic HPNE cells. Inhibition of autophagy in those Verapamil-treated cells stimulates apoptosis. ${ }^{53}$ Although without autophagy analysis, it has been demonstrated that DIL in combination with proteasome inhibitors induces apoptosis in proteasome inhibitor-resistant prostate cancer DU145 cells. ${ }^{30}$ Our and others' results strongly indicate that DHP- and non-DHP-CCBs may affect autophagy and apoptosis differentially in various cancer cells.

Furthermore, several reports have evaluated the clinical efficacy of targeted arterial perfusion of VER and chemotherapeutic agents in the interventional therapy of various cancers. In order to reach a concentration capable of reversing MDR in tumors and avoid cardiac toxicity exceeding the safe concentration (1.0-2.0 $\mu \mathrm{M})$, targeted arterial perfusion of VER and chemotherapeutic agents were performed for tumor chemotherapy. It was found that VER via targeted arterial infusion could effectively reverse the MDR in primary hepatocellular carcinoma patients and enhanced the efficacy of chemotherapy. ${ }^{54}$ In patients with advanced gastric cancer, chemotherapy is more effective when combined with targeted arterial infusion of VER, leading to extended patient survival and improved quality of life. ${ }^{55}$ Furthermore, targeted arterial perfusion of VER and chemotherapeutic drugs can improve clinical symptoms of patients with advanced lung cancer and increase the efficacy of chemotherapeutic agents. $^{56}$

Despite chemotherapy, advanced NSCLC is usually associated with poor prognosis. When patients have chemoresistance and hypertension concurrently, the outcome may be affected by drug/drug interactions. Although oral administration of non-DHP CCBs may not reach a concentration capable of reversing MDR in tumors, the metastatic lung cancer cells in systemic circulation may be sensitized when combined with chemotherapy, leading to improved survival, ${ }^{25}$ and targeted arterial perfusion of VER and chemotherapeutic agents may more effectively prolong patient survival.

\section{Conclusions}

VER plus DOC/VCR effectively sensitize chemoresistant lung cancer cells to death via autophagy burst and apoptosis, and NIF has little anticancer effect than VER or DIL. Our data suggest that patients with advanced lung cancer and hypertension should be carefully monitored with chemotherapy and Non-DHP type CCBs may provide a better anticancer effect.

\section{Abbreviations}

NSCLC; non-small cell lung cancer; ABCB1; ATPbinding cassette sub-family $\mathrm{B}$ member 1; DOC; Docetaxel; MTs; microtubules; VCR; vincristine; MDR; multidrug resistance; $\mathrm{CCBs;} \mathrm{calcium} \mathrm{channel}$ blockers; TD; thiazide diuretics; ACEi; angiotensinconverting enzyme inhibitors; ARBs; angiotensin II receptor antagonists; BBs; beta blockers; DHP; dihydropyridine; non-DHP; non-Dihydropyridine; NIF; Nifedipine; VER; Verapamil; DIL; Diltiazem; mTOR; Mammalian target of rapamycin; MNC; mononuclear cells; SLE; lupus erythematosus; P-gp; P-glycoprotein; ELISA; Enzyme-linked immunosorbent assay; PI; propidium iodide; AVOs; acidic vesicular organelles; ATG5; autophagy-related 5; VSV-G; Vesicular stomatitis virus-G protein; shRNA; Small hairpin RNA; shLuc; shRNA specific for luciferase gene; CQ; chloroquine; SD; standard deviation; c-PARP; Cleavage form of Poly (ADP-ribose) polymerase; LC3B II; microtubule-associated protein $1 \mathrm{~A} / 1 \mathrm{~B}$-light chain 3 phosphatidylethanolamine conjugated B II.

\section{Data Sharing Statement}

The data used and/or analyzed during the current study are available from the corresponding author on reasonable request.

\section{Acknowledgments}

We would like to thank the staff of the Instrument Center of Chung Shan Medical University for their technical support.

\section{Author Contributions}

BS and LY performed the experiments; interpretation of the results. DG, GT and TT designed the experiments, collected data and analyzed. BS, GT and TT wrote the paper. DG and GT revised the manuscript. All authors contributed to data analysis, drafting or revising the article, gave final approval of the version to be published, and agree to be accountable for all aspects of the work. All authors read and approved the final manuscript.

\section{Funding}

This work was supported by grant (CSMU-TSMH-105-02) and Ditmanson Medical Foundation Chia-Yi Christian Hospital (Grant No. R106-031). 


\section{Disclosure}

The authors declare that there are no potential conflicts of interest.

\section{References}

1. Siegel RL, Miller KD, Jemal A. Cancer statistics, 2018. CA Cancer J Clin. 2018;68(1):7-30. doi:10.3322/caac.21442

2. Baird RD, Kaye SB. Drug resistance reversal-are we getting closer? Eur J Cancer. 2003;39(17):2450-2461. doi:10.1016/S0959-8049(03)00619-1

3. Chiu LY, Ko JL, Lee YJ, Yang TY, Tee YT, Sheu GT. L-type calcium channel blockers reverse docetaxel and vincristine-induced multidrug resistance independent of ABCB1 expression in human lung cancer cell lines. Toxicol Lett. 2010;192(3):408-418. doi:10.1016/j. toxlet.2009.11.018

4. Fitzpatrick FA, Wheeler R. The immunopharmacology of paclitaxel (Taxol), docetaxel (Taxotere), and related agents. Int Immunopharmacol. 2003;3(13-14):1699-1714. doi:10.1016/j. intimp.2003.08.007

5. Dumontet C, Sikic BI. Mechanisms of action of and resistance to antitubulin agents: microtubule dynamics, drug transport, and cell death. J Clin Oncol. 1999;17(3):1061-1070. doi:10.1200/JCO.1999. 17.3.1061

6. Davies AM, Lara Jr PN Jr., Mack PC, Gandara DR. Docetaxel in non-small cell lung cancer: a review. Expert Opin Pharmacother. 2003;4(4):553-565. doi:10.1517/14656566.4.4.553

7. Green MR. Perspectives and opportunities: docetaxel in the current and future treatment of non-small cell lung cancer. Semin Oncol. 2002;29(3 Suppl 12):17-21. doi:10.1053/sonc.2002.34259

8. Kobayashi S, Okada S, Hasumi T, Sato N, Fujimura S. Combined modality therapy including surgery for stage III small-cell lung cancer on the basis of the sensitivity assay in vitro. Surg Today. 2000;30(2):127-133. doi:10.1007/PL00010060

9. Wood KW, Cornwell WD, Jackson JR. Past and future of the mitotic spindle as an oncology target. Curr Opin Pharmacol. 2001;1(4):370377. doi:10.1016/S1471-4892(01)00064-9

10. Kartner N, Riordan JR, Ling V. Cell surface P-glycoprotein associated with multidrug resistance in mammalian cell lines. Science (New York, NY). 1983;221(4617):1285-1288. doi:10.1126/science.6137059

11. McGrogan BT, Gilmartin B, Carney DN, McCann A. Taxanes, microtubules and chemoresistant breast cancer. Biochim Biophys Acta. 2008;1785(2):96-132. doi:10.1016/j.bbcan.2007.10.004

12. Ogihara T, Kikuchi K, Matsuoka H, et al. The Japanese society of hypertension guidelines for the management of hypertension (JSH 2009). Hypertens Res. 2009;32(1):3-107. doi:10.1038/hr.2009.34

13. Katz AM. Pharmacology and mechanisms of action of calcium-channel blockers. J Clin Hypertens. 1986;2(3 Suppl):28S-37S.

14. Elliott WJ, Ram CV. Calcium channel blockers. J Clin Hypertens (Greenwich). 2011;13(9):687-689. doi:10.1111/j.1751-7176.2011. 00513.x

15. Coogan PF. Calcium-channel blockers and breast cancer: a hypothesis revived. JAMA Intern Med. 2013;173(17):1637-1638. doi:10. 1001/jamainternmed.2013.9069

16. Krishna R, Mayer LD. Multidrug resistance (MDR) in cancer. Mechanisms, reversal using modulators of MDR and the role of MDR modulators in influencing the pharmacokinetics of anticancer drugs. Eur J Pharm Sci. 2000;11(4):265-283. doi:10.1016/S09280987(00)00114-7

17. Tsuruo T, Iida H, Nojiri M, Tsukagoshi S, Sakurai Y. Circumvention of vincristine and Adriamycin resistance in vitro and in vivo by calcium influx blockers. Cancer Res. 1983;43(6):2905-2910.

18. Tsuruo T, Iida H, Tsukagoshi S, Sakurai Y. Overcoming of vincristine resistance in P388 leukemia in vivo and in vitro through enhanced cytotoxicity of vincristine and vinblastine by verapamil. Cancer Res. 1981;41(5):1967-1972.
19. Ozols RF, Cunnion RE, Klecker RW Jr., et al. Verapamil and adriamycin in the treatment of drug-resistant ovarian cancer patients. $J$ Clin Oncol. 1987;5(4):641-647. doi:10.1200/JCO.1987.5.4.641

20. Cairo MS, Siegel S, Anas N, Sender L. Clinical trial of continuous infusion verapamil, bolus vinblastine, and continuous infusion VP-16 in drug-resistant pediatric tumors. Cancer Res. 1989;49(4):10631066.

21. Salmon SE, Dalton WS, Grogan TM, et al. Multidrug-resistant myeloma: laboratory and clinical effects of verapamil as a chemosensitizer. Blood. 1991;78(1):44-50. doi:10.1182/blood.V78.1.44.44

22. Timcheva CV, Todorov DK. Does verapamil help overcome multidrug resistance in tumor cell lines and cancer patients? J Chemother. 1996;8(4):295-299. doi:10.1179/joc.1996.8.4.295

23. Belpomme D, Gauthier S, Pujade-lauraine E, et al. Verapamil increases the survival of patients with anthracycline-resistant metastatic breast carcinoma. Ann Oncol. 2000;11(11):1471-1476. doi:10.1023/A:1026556119020

24. Millward MJ, Cantwell BM, Munro NC, Robinson A, Corris PA, Harris AL. Oral verapamil with chemotherapy for advanced nonsmall cell lung cancer: a randomised study. Br J Cancer. 1993;67 (5):1031-1035. doi:10.1038/bjc.1993.189

25. Holmes S, Griffith EJ, Musto G, Minuk GY. Antihypertensive medications and survival in patients with cancer: a population-based retrospective cohort study. Cancer Epidemiol. 2013;37(6):881-885. doi:10.1016/j.canep.2013.09.001

26. Mizushima N, Komatsu M. Autophagy: renovation of cells and tissues. Cell. 2011;147(4):728-741. doi:10.1016/j.cell.2011.10.026

27. Dikic I, Elazar Z. Mechanism and medical implications of mammalian autophagy. Nat Rev Mol Cell Biol. 2018;19(6):349-364. doi:10.1038/s41580-018-0003-4

28. Williams A, Sarkar S, Cuddon P, et al. Novel targets for Huntington's disease in an mTOR-independent autophagy pathway. Nat Chem Biol. 2008;4(5):295-305. doi:10.1038/nchembio.79

29. Lu MC, Lai NS, Yu HC, Hsieh SC, Tung CH, Yu CL. Nifedipine suppresses Th1/Th2 cytokine production and increased apoptosis of anti-CD3 + anti-CD28-activated mononuclear cells from patients with systemic lupus erythematosus via calcineurin pathway. Clin Immunol. 2008;129(3):462-470. doi:10.1016/j.clim.2008.08.001

30. Kaddour-djebbar I, Choudhary V, Lakshmikanthan V, et al. Diltiazem enhances the apoptotic effects of proteasome inhibitors to induce prostate cancer cell death. J Pharmacol Exp Ther. 2012;341 (3):646-655. doi:10.1124/jpet.111.188151

31. Roger S, Le Guennec JY, Besson P. Particular sensitivity to calcium channel blockers of the fast inward voltage-dependent sodium current involved in the invasive properties of a metastatic breast cancer cell line. Br J Pharmacol. 2004;141(4):610-615. doi:10.1038/sj.bjp.07 05649

32. Chiu LY, Hu ME, Yang TY, et al. Immunomodulatory protein from ganoderma microsporum induces pro-death autophagy through AktmTOR-p70S6K pathway inhibition in multidrug resistant lung cancer cells. PLoS One. 2015;10(5):e0125774. doi:10.1371/journal.pone.01 25774

33. Boulares AH, Yakovlev AG, Ivanova V, et al. Role of poly(ADPribose) polymerase (PARP) cleavage in apoptosis. Caspase 3-resistant PARP mutant increases rates of apoptosis in transfected cells. J Biol Chem. 1999;274(33):22932-22940. doi:10.1074/jbc.274.33.22932

34. Klionsky DJ, Abeliovich H, Agostinis P, et al. Guidelines for the use and interpretation of assays for monitoring autophagy in higher eukaryotes. Autophagy. 2008;4(2):151-175. doi:10.4161/auto.5338

35. Hsin IL, Sheu GT, Jan MS, et al. Inhibition of lysosome degradation on autophagosome formation and responses to GMI, an immunomodulatory protein from Ganoderma microsporum. $\mathrm{Br} J$ Pharmacol. 2012;167(6):1287-1300. doi:10.1111/j.1476-5381.2012.02073.x

36. Staskiewicz L, Thorburn J, Morgan MJ, Thorburn A. Inhibiting autophagy by shRNA knockdown: cautions and recommendations. Autophagy. 2013;9(10):1449-1450. 
37. Mauthe M, Orhon I, Rocchi C, et al. Chloroquine inhibits autophagic flux by decreasing autophagosome-lysosome fusion. Autophagy. 2018;14(8):1435-1455. doi:10.1080/15548627.2018.1474314

38. Bundy JD, Li C, Stuchlik P, et al. Systolic blood pressure reduction and risk of cardiovascular disease and mortality: a systematic review and network meta-analysis. JAMA Cardiol. 2017;2(7):775-781. doi:10.1001/jamacardio.2017.1421

39. Padwal RS, Bienek A, McAlister FA, Campbell NR; Outcomes Research Task Force of the Canadian Hypertension Education P. Epidemiology of hypertension in canada: an update. Can J Cardiol. 2016;32(5):687-694. doi:10.1016/j.cjca.2015.07.734

40. Lawes CM, Vander Hoorn S, Rodgers A; International Society of H. Global burden of blood-pressure-related disease, 2001. Lancet. 2008;371(9623):1513-1518. doi:10.1016/S0140-6736(08)60655-8

41. McManus RJ, Caulfield M, Williams B. National Institute for $\mathrm{H}$, Clinical E. NICE hypertension guideline 2011: evidence based evolution. BMJ. 2012;344:e181. doi:10.1136/bmj.e181

42. Grimaldi-bensouda L, Klungel O, Kurz X, et al. Calcium channel blockers and cancer: a risk analysis using the UK Clinical Practice Research Datalink (CPRD). BMJ Open. 2016;6(1):e009147. doi:10.1136/bmjopen-2015-009147

43. Raebel MA, Zeng C, Cheetham TC, et al. Risk of breast cancer with long-term use of calcium channel blockers or angiotensin-converting enzyme inhibitors among older women. Am J Epidemiol. 2017;185 (4):264-273. doi:10.1093/aje/kww217

44. Chang $\mathrm{CH}$, Chiang $\mathrm{CH}$, Yen $\mathrm{CJ}$, Wu LC, Lin JW, Lai MS. Antihypertensive agents and the risk of breast cancer in women aged 55 years and older: a nested case-control study. J Hypertens. 2016;34 (3):558-566; discussion 566. doi:10.1097/HJH.0000000000000813

45. Li W, Shi Q, Wang W, Liu J, Li Q, Hou F. Calcium channel blockers and risk of breast cancer: a meta-analysis of 17 observational studies. PLoS One. 2014;9(9):e105801. doi:10.1371/journal.pone.0105801

46. Li CI, Daling JR, Tang MT, Haugen KL, Porter PL, Malone KE. Use of antihypertensive medications and breast cancer risk among women aged 55 to 74 years. JAMA Intern Med. 2013;173(17):1629-1637. doi:10.1001/jamainternmed.2013.9071

47. Sun H, Zhuang RY, Li T, Zheng YT, Cai WM. No association between calcium channel blockers and survival in patients with cancer: a systematic review and meta-analysis. Asian Pac J Cancer Prev. 2016;17(8):3917-3921.
48. Chen L, Chubak J, Boudreau DM, Barlow WE, Weiss NS, Li CI. Use of antihypertensive medications and risk of adverse breast cancer outcomes in a SEER-medicare population. Cancer Epidemiol Biomarkers Prev. 2017;26:1603-1610. doi:10.1158/1055-9965.EPI-17-0346

49. Kim SA, Moon H, Roh JL, et al. Postdiagnostic use of beta-blockers and other antihypertensive drugs and the risk of recurrence and mortality in head and neck cancer patients: an observational study of 10,414 person-years of follow-up. Clin Transl Oncol. 2017;19 (7):826-833. doi:10.1007/s12094-016-1608-8

50. Wong MC, Tam WW, Lao XQ, et al. The incidence of cancer deaths among hypertensive patients in a large Chinese population: a cohort study. Int J Cardiol. 2015;179:178-185. doi:10.1016/j.ijcard.2014.10.028

51. Bjorkoy G, Lamark T, Brech A, et al. p62/SQSTM1 forms protein aggregates degraded by autophagy and has a protective effect on huntingtin-induced cell death. J Cell Biol. 2005;171(4):603-614. doi: $10.1083 /$ jcb.200507002

52. Cohen-kaplan V, Livneh I, Avni N, et al. p62- and ubiquitin-dependent stress-induced autophagy of the mammalian $26 \mathrm{~S}$ proteasome. Proc Natl Acad Sci U S A. 2016;113(47):E7490-E7499. doi:10.1073/ pnas. 1615455113

53. Kania E, Pajak B, O'prey J, et al. Verapamil treatment induces cytoprotective autophagy by modulating cellular metabolism. FEBS J. 2017;284(9):1370-1387. doi:10.1111/febs.2017.284.issue-9

54. Huang J, Duan Q, Fan P, et al. Clinical evaluation of targeted arterial infusion of verapamil in the interventional chemotherapy of primary hepatocellular carcinoma. Cell Biochem Biophys. 2011;59(2):127132. doi:10.1007/s12013-010-9125-9

55. Ning Z, Chen D, Liu A, et al. Efficacy of chemotherapy combined with targeted arterial infusion of verapamil in patients with advanced gastric cancer. Cell Biochem Biophys. 2014;68(1):195-200. doi:10.1007/s12013-013-9689-2

56. Huang J, Zhang T, Ma K, et al. Clinical evaluation of targeted arterial perfusion of verapamil and chemotherapeutic drugs in interventional therapy of advanced lung cancer. Cancer Chemother Pharmacol. 2013;72(4):889-896. doi:10.1007/s00280-013-2271-1

\section{Publish your work in this journal}

Cancer Management and Research is an international, peer-reviewed open access journal focusing on cancer research and the optimal use of preventative and integrated treatment interventions to achieve improved outcomes, enhanced survival and quality of life for the cancer patient.
The manuscript management system is completely online and includes a very quick and fair peer-review system, which is all easy to use Visit http://www.dovepress.com/testimonials.php to read real quotes from published authors. 